\title{
DE PLANTIS LEGIONENSIBUS. NOTA III
}

\author{
E. PUENTE, M. J. LOPEZ-PACHECO \& T. E. DIAZ-GONZALEZ
}

RESUMEN: Como continuación de las anteriores notas floristicas, se complementa el catálogo provincial con una aocena de táxones, resultado de diversas recolecciones botánicas efectuadas por distintas zonas del territorio leonés.

SUMMARY: As following the former check-list notes on León area, twelve taxa are recorded by the firs time for this area.

Aquilegia pyrenaica DC. subsp. discolor (Levier \& Leresche) Pereda

\& Laínz, Bol. Inst. Est. Ast. Ser. C. 5: 12 (1962)

LEON: Pico Huevo 30TTN96, 19.VII.1979 (LEB 10851) sobre calizas.

Aportamos la cita más occidental para la Cordillera Cantábrica, pues se conocía de los Picos de Europa 30TUN48 y 58 (cfr. Laínz \& cols., 1962 y Lainz, 1981 y 1982) y de la Peña del Viento (Caso, Asturias) 30TUN07 (Díaz González \& Fernández Prieto, 1981).

Papaver rhoeas L. var. trichocarpum Pamp., Boll. Soc. Brot. Ital. 13 (1914)

LEON: Rioscuro 29TQH25, 24.VI.1983 (LEB 16063) en bordes de carretera.

A esta variedad descrita por Pampanini, sobre materiales procedentes de l'Ouadi Tentsiona en la región de Tarhouna (Tripolitaine), llevamos nuestros ejemplares.

Dicho taxon se caracteriza por poseer ovario y cápsula con setas esparcidas, tallos entera y densamente cubiertos de setas extendidas y hojas con lóbulo terminal más grande que los laterales, extendidos y todos irregularmente dentado-serrulados (cfr. Maire, 1964), lo cual concuerda con lo observado en nuestros ejemplares.

Parece ser la primera cita provincial y peninsular. 
Papaver x hungaricum Borbás, Balaton Növényföldr. (1900)

$(=$ P. $x$ exspectatum Fedde; P. dubium L. X P. rhoeas L.)

LEON: Villaseca de Laciana 29TQH25, 5.VI.1983 (LEB 15844) en márgenes de carretera.

Nuestros materiales presentan cápsula subglobosa, redondeada en la base, glauca o de tonalidad violácea como el Papaver rhoeas L., si bien, el número de radios del disco estigmatífero, así como todos los restantes caracteres, corresponden a Papaver dubium $\mathrm{L}$.

Astragalus danicus Retz., Obs. Bot. 3:41 (1783)

LEON: La Cueta 29TQH36, 4.IX.1983 (LEB 18833) en pastizales psicroxerófilos sobre sustrato calizo a $1900 \mathrm{~m} . \mathrm{s} . \mathrm{m}$. (Festucion burnatii).

Era conocida únicamente en la Cantábrica de la Vega de Cerveriz (Saliencia, Somiedo, Asturias) 29TQH37 (Laínz \& cols., 1970 y Fernández Prieto, 1981).

Conviviendo con ella aparecía profusamente Oxytropis foucaudii Gillot, especie señalada por Laínz \& cols. (1973) de los Picos Albos y las Peñas de Orniz (Somiedo, Asturias) 29TQH36.

Hyssopus officinalis L. subsp. canescens (DC.) Briq., Lab. Alp. Marit. 387 (1893)

LEON: Piedrafita de Babia 29TQH26, 6.VII.1982 (LEB 13770) y Cacabillo 29TQH26, 4.IX.1983 (LEB 18820) en pastizales sobre sustrato calcáreo de los márgenes de la carretera.

Aster lanceolatus Willd., Sp. Pl. 3:2050 (1803)

LEON: Villager de Laciana 29TQH15, 8.X.1983 (LEB 18818).

Hemicriptófito originario del Norte de América que hemos encontrado naturalizado en el borde de la carretera. Díaz González \& Fernández Prieto (1978) lo señalan para Asturias.

Aster squamatus (Sprengel) Hieron, Bot. Jahrb. 29:19 (1900)

LEON: Bordes del Lago de Carucedo 29TPH80, 5.X.1983 (LEB 20741). Se herborizó en zonas nitrificadas y ruderalizadas conviviendo con Datura stramonium L., Echinochloa colonum (L.) Link, Hordeum marinum Hudson, Polypogon maritimus Willd., Xanthium strumarium L. y Eragrostis pilosa (L.) Beauv., entre otras.

Dittrichia viscosa (L.) Greuter, Exsicc. Genav. 4:71 (1973) subsp. viscosa

LEON: Ponferrada 29TPH91 (LEB 20757), Quintanilla de Combarros 29TQH31 (LEB 20738), San Miguel de las Dueñas 29TQH01 (LEB 20739) y Bembibre 29TQH12 (LEB 20740) 5.X.1983 en bordes de carretera. 
Helianthus tuberosus L., Sp. Pl. 905 (1753)

LEON: Cuevas del Sil 29TQH15, 8.X.1983 (LEB 18819) en bordes de campos de cultivo. Santander.

Especie oriunda del Brasil que Guinea (1953) ya señaló para

Balsamita major Desf., Actes Soc. Hist. Nat. Paris 1:3 (1792)

LEON: Cospedal de Babia 29TQH46, 20.XI.1983 (LEB 20588)

Hemicriptófito, originario del SW de Asia, que hemos encontrado naturalizado en bordes de campos de cultivo.

Paspalum vaginatum Swartz, Nov. Gen. Sp. Pl. 21 (1788)

LEON: Bordes del Lago de Carucedo 29TPH80, 5.X.1983 (LEB 207 65) en comunidades nitrófilas y ruderalizadas.

Sorghum bicolor (L.) Moench, Meth. 207 (1794)

LEON: Proximidades de Las Ventas de San Juan de Paluezas 29TPH80, 5.X.1983 (LEB 20742 y 20743) en el borde de la carretera.

\section{BIBL IOGRAFIA}

DIAZ GONZALEZ, T.E. \& FERNANDEZ PRIETO, J.A. -1978- Notas sobre la flora astur-leonesa. Rev. Fac. Cienc. Oviedo, 17-19: 303-308.

DIAZ GONZALEZ, T.E. \& FERNANDEZ PRIETO, J.A. -1981- Las plantas vasculares con semillas (Fanerógamas). In Enciclopedia Temática de Asturias I: Botánica: 209-213. Silverio Cañada Editor. Gijón.

FERNANDEZ PRIETO, J.A. -1981- Estudio de la flora y vegetación del concejo de Somiedo. Mem. Tesis Doctoral (inéd.). Fac. Ciencias. Oviedo.

GUINEA, E. -1953- Geografía botánica de Santander. Excma. Diputación Provincial de Santander. Santander.

LAINZ, M. -1981- Flora in Naturaleza y vida de los Picos de Europa: 82121. Incafo.

LAINZ, M. -1982-Mis contribuciones al conocimiento de la flora de Asturias. Inst. Ast. Oviedo.

LAINZ, M. \& cols. -1962- Aportaciones al conocimiento de la flora cántabro-astur, VI. Bol. Inst. Est. Ast. Ser. C, 5: 3-43.

LAINZ, M. \& cols. -1970-Aportaciones al conocimiento de la flora cántabro-astur, IX. Bol. Inst. Est. Ast. Ser. C, 15: 3-45.

LAINZ, M. \& cols. -1973- Aportaciones al conocimiento de la flora cántabro-astur, X. Bol. Inst. Est. Ast. Ser. C, 16: 159-206.

MAIRE, R. -1964- Flore de l'Afrique du Nord, 11: 1-335. Ed. P. Lechevalier. París. 